Article

\title{
Determination of Supercooling Degree, Nucleation and Growth Rates, and Particle Size for Ice Slurry Crystallization in Vacuum
}

\author{
Xi Liu, Kunyu Zhuang, Shi Lin, Zheng Zhang and Xuelai Li * \\ School of Chemical Engineering, Fuzhou University, Fuzhou 350116, China; xi.liu@fzu.edu.cn (X.L.); \\ zhuangkunyu123@126.com (K.Z.); linshi19900205@163.com (S.L.); zzhang_fzu@163.com (Z.Z.) \\ * Correspondence: T99025@fzu.edu.cn
}

Academic Editors: Helmut Cölfen and Mei Pan

Received: 7 April 2017; Accepted: 29 April 2017; Published: 5 May 2017

\begin{abstract}
Understanding the crystallization behavior of ice slurry under vacuum condition is important to the wide application of the vacuum method. In this study, we first measured the supercooling degree of the initiation of ice slurry formation under different stirring rates, cooling rates and ethylene glycol concentrations. Results indicate that the supercooling crystallization pressure difference increases with increasing cooling rate, while it decreases with increasing ethylene glycol concentration. The stirring rate has little influence on supercooling crystallization pressure difference. Second, the crystallization kinetics of ice crystals was conducted through batch cooling crystallization experiments based on the population balance equation. The equations of nucleation rate and growth rate were established in terms of power law kinetic expressions. Meanwhile, the influences of suspension density, stirring rate and supercooling degree on the process of nucleation and growth were studied. Third, the morphology of ice crystals in ice slurry was obtained using a microscopic observation system. It is found that the effect of stirring rate on ice crystal size is very small and the addition of ethylene glycoleffectively inhibits the growth of ice crystals. The results in this paper can provide theoretical guidance and technical support for the development of vacuum icemakers.
\end{abstract}

Keywords: ice slurry; supercooling degree; nucleation rate; growth rate; particle size

\section{Introduction}

Thermal energy storage is used to assist in the effective utilization of thermal energy in industrial applications [1-4]. Ice slurry as anenergy storage medium is a very interesting solution thanks to the high energy storage density and fast cooling capacity [5-7]. The most important issue relating to the wide use of ice slurry cooling technology relates to what is the best method of ice slurry production [7]. There are many methods for making ice slurry, including scraped-surface type, supercooling type, direct-injection or direct heat exchange type, fluidized-bed type, and vacuum type [8-12]. Among these methods, vacuum type, which uses aqueous solution as a refrigerant and employs direct contact heat transfer, has received wide attention in recent years.

Kim et al. [13] studied the conditions for the formation of ice crystals theoretically by the diffusion-controlled evaporation model and the prediction was proved by experiments. Lugo et al. [14] researched the ice-liquid-vapour equilibria data of ammonia and ethanol aqueous solutions experimentally. The measured data were consistent with the thermodynamic models. Asaoka et al. $[15,16]$ proposed a circulating system to produce ice slurry and studied the vapor-liquid equilibrium data to estimate the coefficient of performance of the system with an ethanol solution. Zhang et al. [17] established a model for the process including flash evaporation and ice making in 
vacuum environment. The influencing factors for the binary ice's IPF, such as environmental pressure, droplet size and water temperature, were discussed both analytically and experimentally.

At present, most of the research interests related to vacuum method are focused on heat and mass transfer inside the liquid, as well as the phase equilibrium measurement and equipment optimization. However, the crystallization thermodynamics and kinetics of ice slurry, including the supercooling degree, the nucleation rate and growth rate, the morphology of ice crystals, have not been accurately understood, which have been the main obstacles to the rapid development and wide application of vacuum method. Therefore, it is necessary to determine the above problems and reveal the crystallization behavior of ice slurry under vacuum condition.

The supercooling degree is the driving force for the nucleation and growth of ice crystals. The supercooling degree depends on several operation parameters, such as stirring rate, cooling rate, solution composition, etc. At present, the study of supercooling is mostly conducted under atmospheric pressure $[18,19]$. The supercooling characteristics of ice nucleation in vacuum environments are rarely reported. Nucleation and crystal growth are the two major steps govern the ice slurry production. Accurate modeling of nucleation and growth is an essential prerequisite to the design and control of a vacuum ice slurry production system. Only a few published papers have reported the crystallization kinetics of ice slurry $[20,21]$, but they had small sample sizes and relied on classical nucleation theory. They are not applicable to the formation of ice slurry produced by vacuum. The shape and the size of ice crystals are very important aspects which should be studied, because they influence the operation of ice slurry system. Ice slurry with larger ice crystals will show a slower melt-off rate and need greater power to pump. Some scientists have conducted researches on particle morphology of ice slurry produced by scraped-surface method or fluidized-bed method [11,22,23]. However, the study of the morphology of ice crystals produced by vacuum method has not been taken seriously.

In this work, ethylene glycol aqueous solution served as the ice-making solution, and the supercooling characteristics at different experimental conditions were measured using a vacuum ice slurry production system. The nucleation rate and growth rate of the crystal formation process were discussed in the view of kinetics, and the influence of each parameter on crystallization process was analyzed. At the same time, the morphology of ice crystals was observed, and the influence of stirring rate and initial concentration on the particle size of ice crystals was determined. The objectives of this research are to explore the rules of ice slurry crystallization in vacuum and provide theoretical and technical support for the ice slurry production.

\section{Theory}

\subsection{Nucleation and Growth Rate}

For nucleation two different mechanism are distinguished; the homogeneous and the heterogeneous nucleation. In homogeneous nucleation embryos are formed internally in the supercooled liquid containing only water molecules. In heterogeneous nucleation a foreign substrate initiates nuclei formation. At present, a number of authors suggest that most primary nucleation in industrial crystallizers is heterogeneous rather than homogeneous and empirical relationships such as [24-28]:

$$
B=K_{\mathrm{N}} M_{\mathrm{T}}{ }^{a} N_{\mathrm{P}}{ }^{b} \Delta C^{c}
$$

where $K_{\mathrm{N}}$ is the nucleation rate constant, $M_{\mathrm{T}}$ is the suspension density, $N_{\mathrm{P}}$ is the stirring rate, $\Delta C$ is the driving force of nucleation. In the process of ice slurry production, $\Delta C$ equals to supercooling degree $\Delta t$. Equation (1), therefore, can be rewritten as:

$$
B=K_{\mathrm{N}} M_{\mathrm{T}}^{a} N_{\mathrm{P}}^{b} \Delta t^{c}
$$


An empirical correlation is frequently employed to describe the crystal growth rate as a function of the supercooling degree $\Delta t$, as follows:

$$
G=K_{\mathrm{G}} \Delta t^{g}
$$

where $K_{\mathrm{G}}$ is the growth rate constant.

\subsection{Population Balance}

To evaluate the nucleation and growth kinetics, a population balance model that describes the crystallization process has been employed. The following assumptions are made: (1) growth rate is independent of crystal size and the McCabe's " $\Delta \mathrm{L}$ rule" is valid; (2) agglomeration and breakage are not significant; (3) the volume of the solution is invariable. Hence, the general population balance equation can be expressed as $[27,28]$ :

$$
\frac{\partial n}{\partial t}+G \frac{\partial n}{\partial L}=0
$$

The $k$ th moment of the population density function can be defined as:

$$
\mu_{k}=\int_{0}^{\infty} n L^{k} d L
$$

where $L$ is the ice crystal size and $n$ is the population density which can be calculated from the follow relations:

$$
n_{i}=\frac{M_{\mathrm{T}} \Delta V_{i}}{\rho_{\mathrm{c}} k_{\mathrm{v}}{\overline{L_{i}}}^{3} \Delta L_{i}}
$$

where $\Delta V_{i}$ is the volume fraction in $i$ th region, $\overline{L_{i}}$ is the average ice crystal size in the given size range, $\Delta L_{i}$ is the width between two crystal size region, $\rho_{\mathrm{c}}$ is the crystal density, $k_{\mathrm{v}}$ is the volume shape factor.

By the method of moment transform, the Equation (4) can be transformed from a first-order nonlinear partial differential equation to a group of constant differential equations:

$$
\begin{gathered}
\frac{d \mu_{0}}{d t}=B \\
\frac{d \mu_{1}}{\overline{\mu_{0}} d t}=G
\end{gathered}
$$

When the time interval is very short, the relationship between the moment value and the time will accord with the linearity. Thus, the kinetic rate can be expressed as:

$$
\begin{aligned}
& \bar{B}=\frac{\Delta \mu_{0}}{\Delta t} \\
& \bar{G}=\frac{\Delta \mu_{1}}{\overline{\mu_{0}} \Delta t}
\end{aligned}
$$

\section{Materials and Methods}

\subsection{Materials}

Ethylene glycol (purity $\geq 99.0 \%$ ) was purchased from Sinopharm Chemical Reagent Co., Ltd. (Shanghai, China) Distilled water has served as solvent.

\subsection{Measurement of Supercooling Degree}

A schematic of the experimental apparatus for producing ice slurry is shown in Figure 1. The apparatus consists of a vacuum pump, a vacuum chamber, a magnetic stirrer, a vapor condenser, a $\mathrm{T}$ 
thermocouple (accuracy: $\pm 0.2 \mathrm{~K}$ ), a pressure transducer (accuracy: $\pm 0.04 \mathrm{mbar}$ ), and data acquisition systems for recording the temperature and pressure. The vacuum pump could deliver a maximum volume flow rate of $2 \mathrm{~L} \cdot \mathrm{s}^{-1}$ at $100 \mathrm{kPa}$ and could reach a maximum vacuum of $6 \times 10^{-2} \mathrm{~Pa}$.

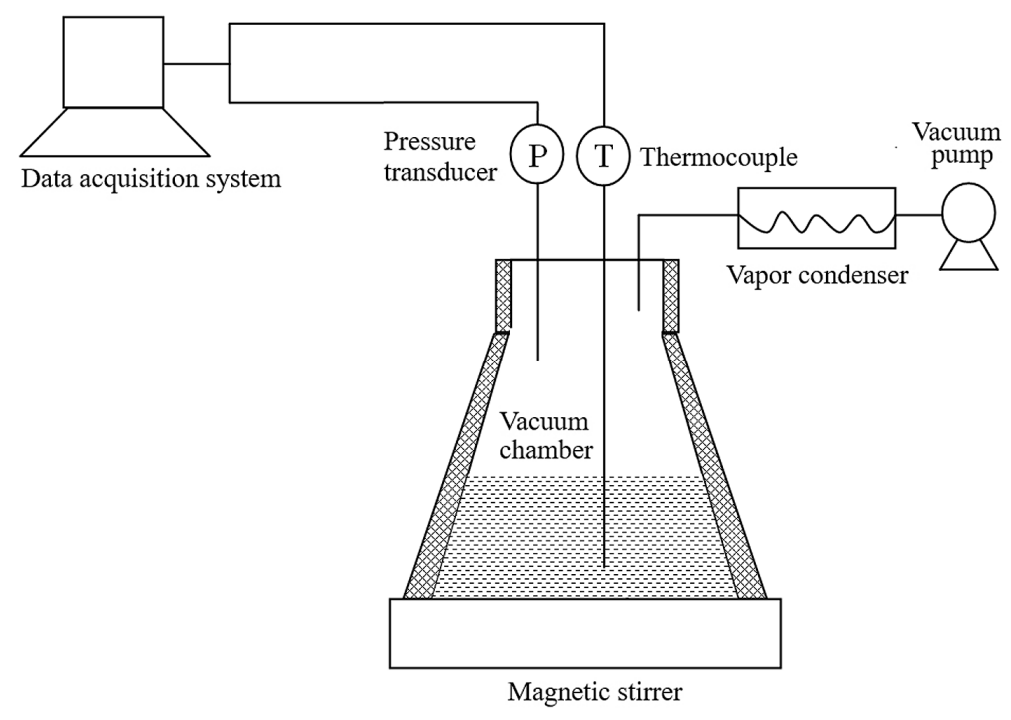

Figure 1. Schematic of ice slurry production system.

The changes of pressure and temperature versus time during the process of ice slurry production are shown in Figure 2. At the beginning, the aqueous solution evaporated under low-pressure conditions, and the remaining solution was cooled as a consequence of the latent heat of evaporation. When the temperature dropped below the freezing point $\left(T=T_{0}, p=p_{0}\right)$, the aqueous solution entered the supercooling state. After a few minutes, the supercooling state broke and the ice slurry formed immediately. Latent heat released by ice enabled the temperature of the solution to rise to freezing, and the initiation of formation of ice slurry was monitored by a small jump of temperature and pressure data.

The temperature and pressure curves in Figure 2 show that the variation of the two state parameters is very similar during the ice making process, suggesting that these two parameters can be used to monitor the changes in the state of the solution in the vacuum chamber. The solution in the chamber was stirred throughout the experiment, so the thermocouple was affected by the strike of the liquid, which caused temperature variation and fluctuations in the temperature curve. Observation of the pressure curve, on the other hand, showed no random fluctuations. This is because the pressure monitored by pressure transducer is the gas pressure, which is not affected by the liquid stirring. For this reason, pressure is chosen as the characteristic parameter to characterize the supercooling degree of ice crystallization in this work. The minimum pressure during the pressure relieving process is defined as relief pressure of supercooling $p_{\min }$. The pressure at which the ice crystal begins to emerge is defined as phase transition pressure $p_{0}$. The difference between $p_{0}$ and $p_{\min }, \Delta p$, is named "supercooling crystallization pressure difference", which is the evaluation parameter of supercooling. The freezing behavior of solution shows a certain randomness, it is therefore necessary to repeat the same experiment several times under the same conditions. In this study, all experiments performed under the same conditions were performed 40 times and averaged to ensure the reliability of the results. 


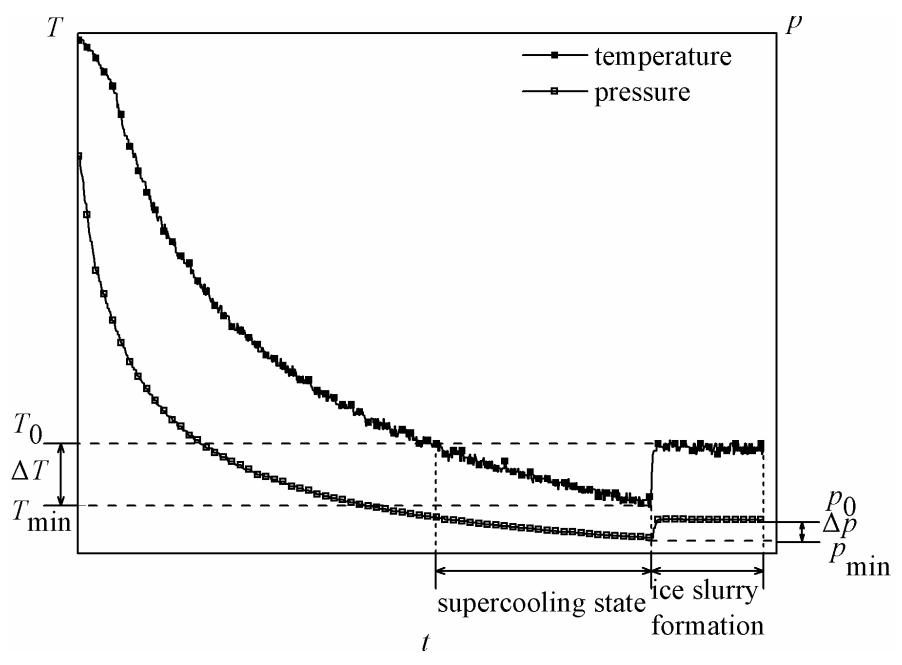

Figure 2. Variations of pressure and temperature during the process of ice slurry production.

\subsection{Measurement of Crystal Morphology}

The ice crystals were observed based on a microscopic observation device as shown in Figure 3. This device was inspired by previous work on ice slurries $[23,29,30]$. During the observation process, the bottom plate of glass was kept at $-2{ }^{\circ} \mathrm{C}$ to prevent ice from melting by heat from the backlight and environment. All the observation processes were performed within $3 \mathrm{~min}$, so the effect of Ostwald ripening, particle agglomeration and particle melting could be ignored. The typical image of ice slurry crystals is shown in Figure 4. Several images were taken and the total number of ice crystals for each test was at least 400 . The images were processed by the image software ImageJ. Because the ice crystals appeared only as 2D-projections in the images, the equivalent circular diameter of each ice crystal was considered its length. This equivalent diameter $D$ of ice crystals was calculated using the surface area of ice crystal 2D-projection $A_{i}$, as proposed in a previous work [26]:

$$
D=\sqrt{\frac{4 A_{i}}{\pi}}
$$

The average crystal diameter was computed using the equivalent diameter of each crystal and the total number of crystals analyzed:

$$
D=\frac{1}{N} \sum_{N=1}^{N} D_{\text {Feret }, i}
$$

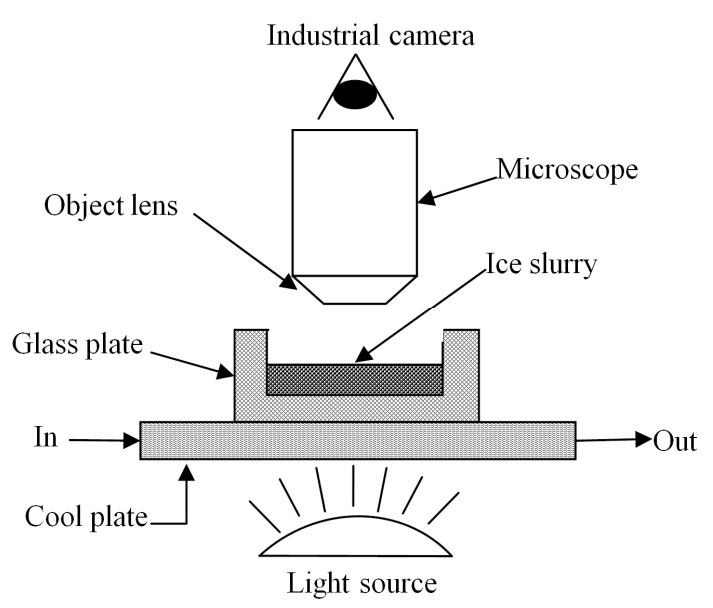

Figure 3. Ice crystal observation system. 


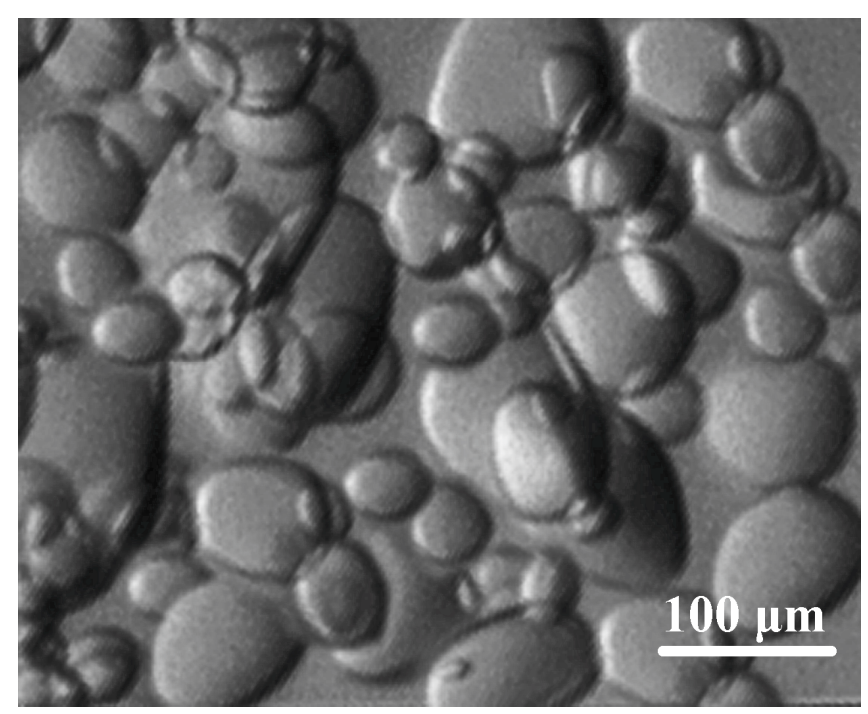

Figure 4. Photograph of the ice crystals in ice slurry.

\subsection{Measurement of Crystallization Kinetics}

The crystallization kinetics of ethylene glycol aqueous solution was determined experimentally using the vacuum ice slurry production system shown in Figure 1. The stirring rates selected in the experiment were 200, 300, and $400 \mathrm{rpm}$. Then vacuum chamber was filled with $20 \mathrm{~mL}$ ethylene glycol aqueous solution at different concentrations, and the vacuum pump, pressure collection system were turned on to observe the pressure change. The pressure jump observed in the system served as an indicator for the occurrence of crystallization. When crystallization time reached the default measurement time, the vacuum pump was turned off to allow sampling. Six samples were taken at the same stirring rate. Degree of supercooling, suspension density and particle size of ice crystals were measured for each sample.

Here the degree of supercooling refers to the difference between the measured temperature and the theoretical temperature calculated at the three-phase equilibrium state. The ethylene glycol aqueous solution is nonvolatile, so the temperature-pressure relationship of the three-phase equilibrium can be described by the vapor-solid equilibrium equation of ice [14]. In this way, the measured pressure data are substituted into the vapor-solid equilibrium equation of ice to determine the phase equilibrium temperature in theory. The measurement of the suspension density was based on the energy conservation principle. There was negligible heat loss during the measurement process, and the value of the suspension density was computed by measuring the initial and final temperatures and masses of the sample as mixed with $20 \mathrm{~g}$ hot water at $40{ }^{\circ} \mathrm{C}$. The observation of ice crystals was based on the ice crystal observation system, as shown in Figure 3. All parameters and strategies used for measurement are summarized in Table 1.

Table 1. Summary of measurement parameters and strategies.

\begin{tabular}{cc}
\hline Parameter & Strategy \\
\hline system pressure & pressure transducer \\
system temperature & T thermocouple \\
ice crystal size & microscopic observation system \\
suspension density of ice slurry & energy conservation principle \\
stirring rate & digital-display magnetic stirrer \\
\hline
\end{tabular}




\section{Results andDiscussion}

\subsection{Supercoolling Degree}

The supercooling characteristics of ethylene glycol aqueous solution with initial concentration of $3 \%$ was experimentally measured at stirring rates of 100, 200, 300, 400, and $500 \mathrm{rpm}$, as shown in Figure 5. At different stirring rates, the mean value of the $\Delta p$ is 55.34, 50.36, 51.56, 49.65, 50.34 Pa and the corresponding standard deviation is 6.02, 5.87, 6.33, 5.25 and $5.38 \mathrm{~Pa}$, respectively, which shows that the stirring rate does not significantly affect the supercooling degree of ethylene glycol aqueous solution. The effect of stirring on the ice crystallization is complicated. Stirring can enhance heat transfer, maintain the uniformity of temperature inside the vacuum chamber, and accelerate the probability of molecular contact to form critical nucleus in certain size that can promote the generation of ice crystals; however, an extra-high mixing rate can result in excessive shear forces, and it is possible to accelerate the crushing of the critical nuclei, reducing the possibility of the formation of critical nuclei, which may be detrimental to crystal nucleation and increase the supercooling degree. Saito et al. studied the effects of external factors on supercooling degree [31]. Results showed that stirring, vibration, friction, and forced convection in water had little effect on its supercooling. These results are consistent with the findings of this work.

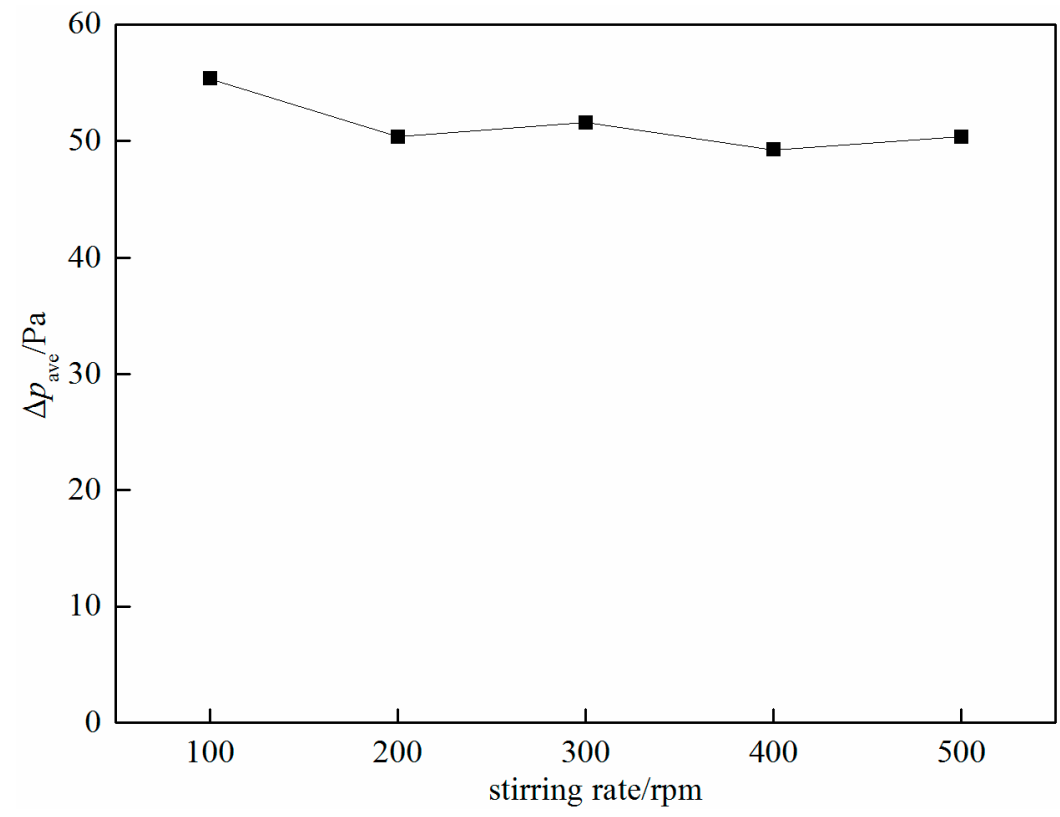

Figure 5. Effects of stirring rate on supercooling crystallization pressure difference.

The cooling rate is defined as the ratio of the $\Delta p$ over the elapsed time in supercooling state. During the experiment, the stirring rate was maintained at $300 \mathrm{rpm}$, and supercooling degree of the ethylene glycol aqueous solution at different cooling rates was measured, as shown in Figure 6. When the cooling rate increased, the $\Delta p$ increased. This is because when the cooling rate was fast, the solution that was already supercooled did not produce nuclei in time. The delay in the nuclei precipitation requires an even lower temperature for ice crystallization and widens the subcooled region. Okawa et al. tested the characteristics of ice formation of supercooled water on metal plate under ambient pressure [18]. Results showed that the degree of supercooling at $2.0 \mathrm{~K} \cdot \mathrm{min}^{-1}$ was much larger than that at $0.2 \mathrm{~K} \cdot \mathrm{min}^{-1}$. These results are consistent with our experiment. 


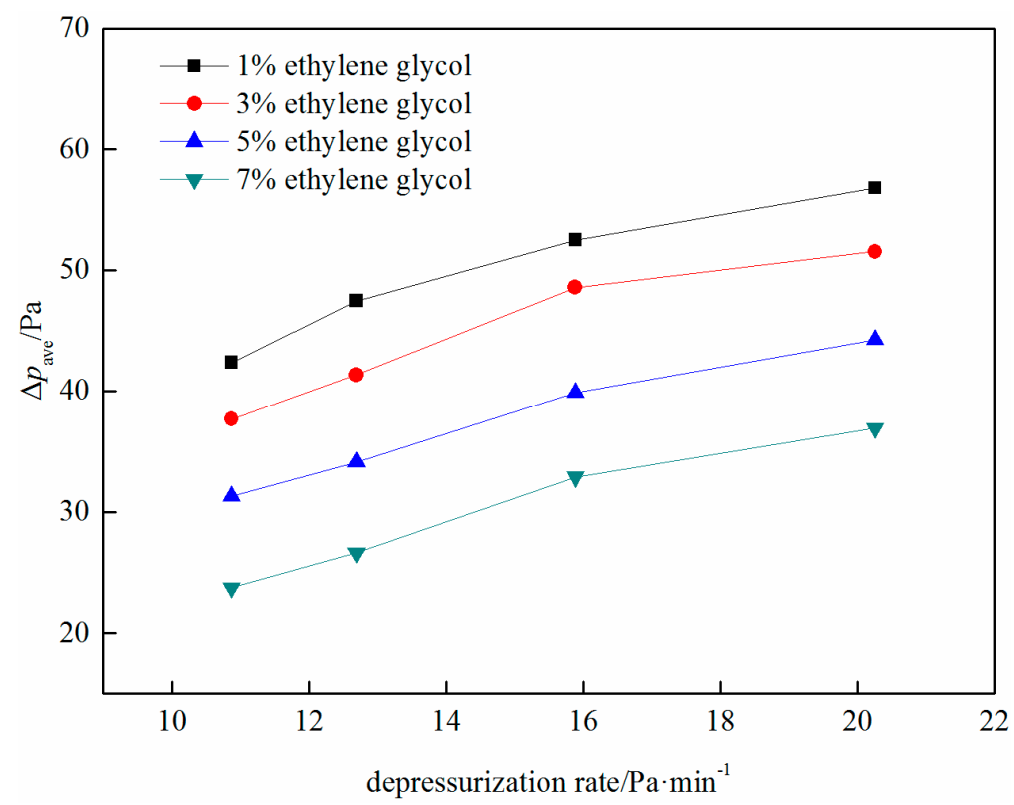

Figure 6. Effects of cooling rate on supercooling crystallization pressure difference.

The supercooling characteristics of ethylene glycol aqueous solution of different concentrations were measured respectively while maintaining the stirring rate at $300 \mathrm{rpm}$. The results are shown in Figure 7. As shown in the figure, the relationship between the width of supercooled region and cooling rate showed the same trend at different cooling rates. At the same cooling rate, the $\Delta p$ of ethylene glycolaqueous solution decreased as the initial concentration of ethylene glycol increased. For example, when the cooling rate was $20.25 \mathrm{~Pa} \cdot \mathrm{min}^{-1}$, the $\Delta p$ of the ethylene glycol aqueous solution with initial concentration of $1 \%$ was $56.81 \mathrm{~Pa}$. When the initial concentration was $7 \%$, the $\Delta p$ dropped to $36.91 \mathrm{~Pa}$, a decrease of $35.03 \%$. Therefore, a higher initial concentration of ethylene glycol aqueous solution results in a smaller $\Delta p$, a narrower supercooled region, and higher unpredictability of the formation of ice crystals. In this way, in view of favoring the control of crystal growth, the solution concentration should be kept as low as possible.

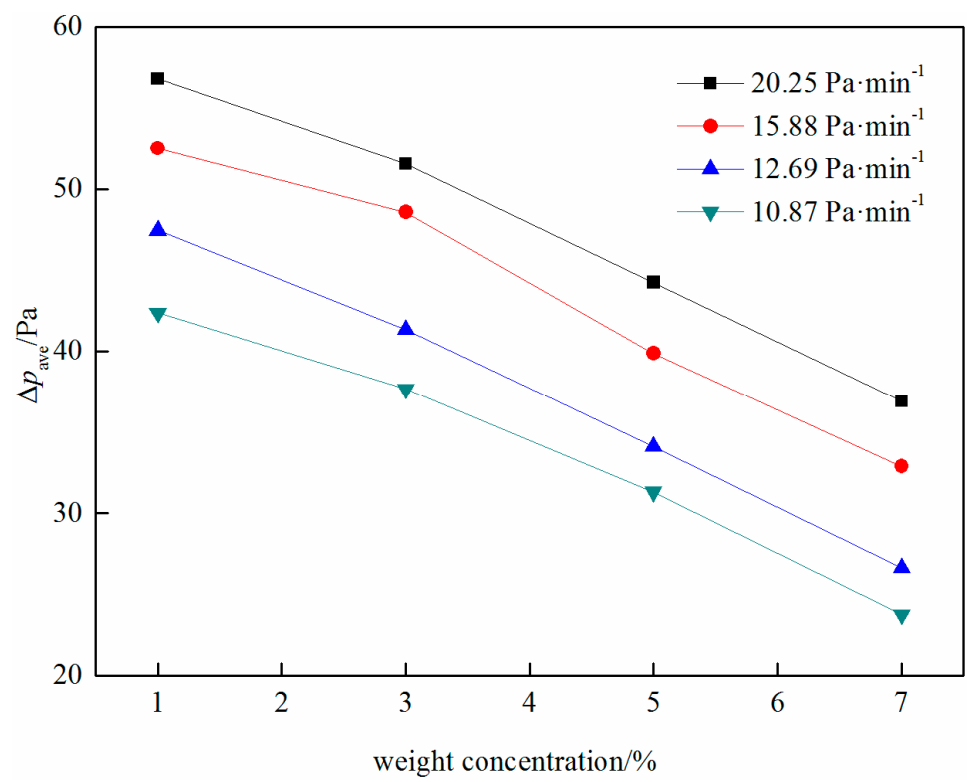

Figure 7. Effects of ethylene glycol concentration on supercooling crystallization pressure difference. 


\subsection{Equations of Nucleation Rateand Growth Rate}

The kinetic parameters of nucleation and growth are obtained by multiple regression analysis of all experimental data, and the equations of nucleation rate and growth rate are established as follows:

$$
\begin{gathered}
B=2.922 \times 10^{10} M_{\mathrm{T}}{ }^{-1.465} N_{\mathrm{P}}{ }^{-0.641} \Delta t^{0.517} R^{2}=0.934 \\
G=1.41 \times 10^{-5} \Delta t^{4.036} R^{2}=0.933
\end{gathered}
$$

A comparison of the regression values from model and the values measured in experiments for the ice nucleation rate and growth rate is shown in Figures 8 and 9, respectively. As shown in the figure, the data points are evenly distributed on both sides of the diagonal, indicating that the established kinetic model can truthfully describe the nucleation and growth kinetics of the ice crystals. Some individual data points deviate from the diagonal, probably because of the ignorance of the agglomeration, Oswald ripening, and crushing behavior of ice crystals in kinetics analysis.

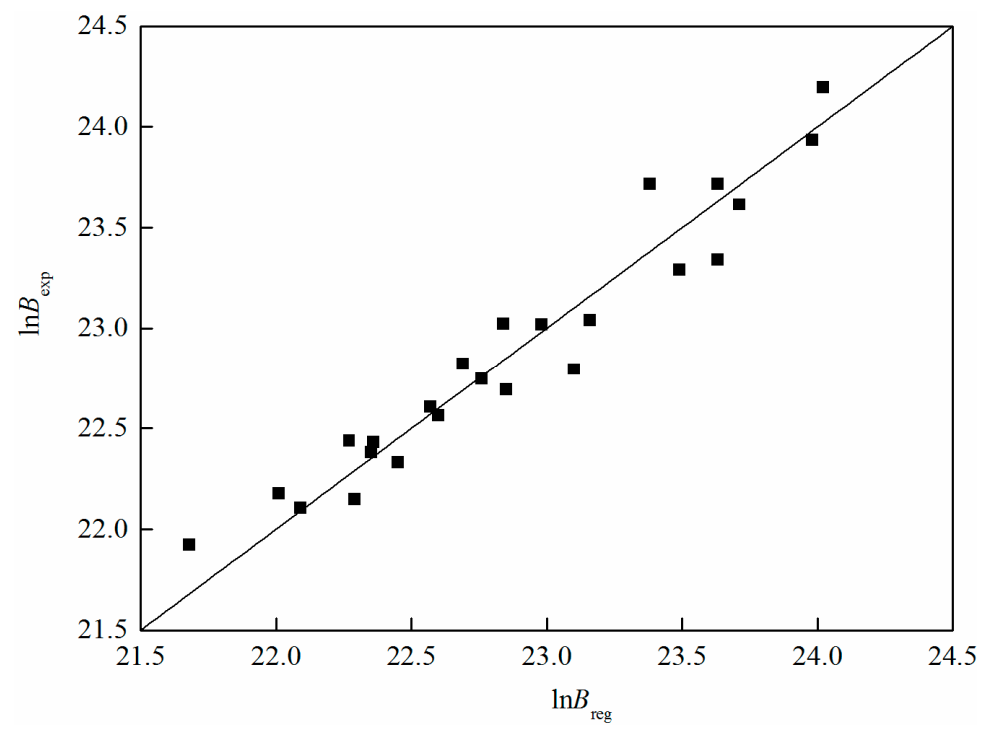

Figure 8. Comparison of nucleation rate between experimental values and regressed values.

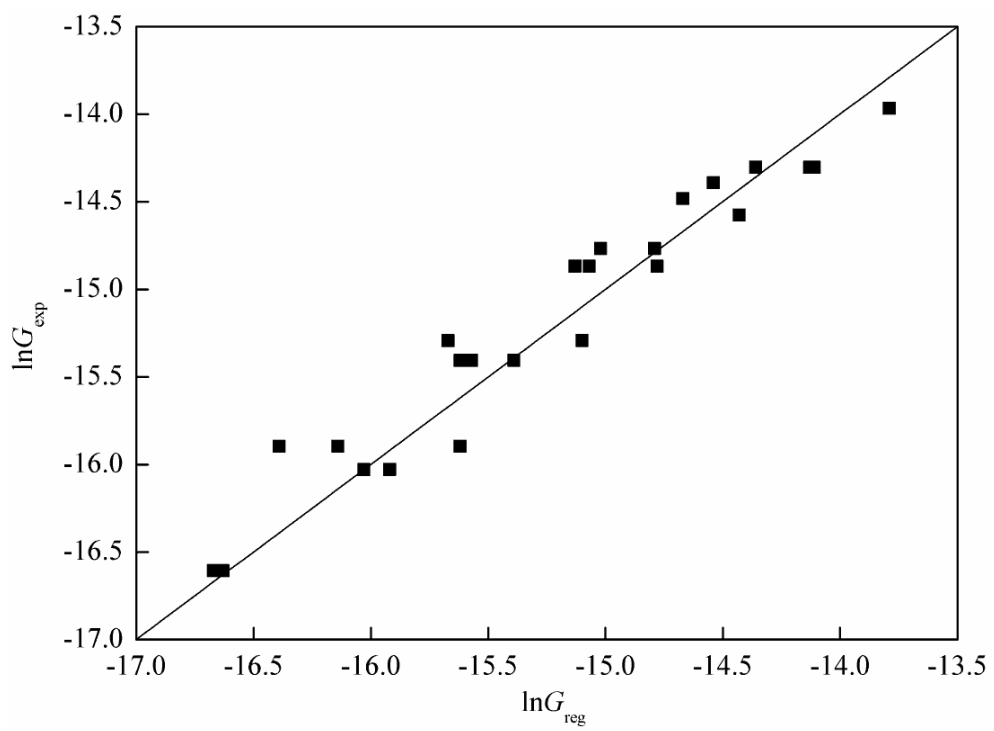

Figure 9. Comparison of growth rate between experimental values and regressed values. 
As shown in Equation (13), the exponent of stirring rate in the nucleation rate equation is -0.641 , which is less than zero, indicating that the higher stirring rate results in the lower nucleation rate in the stirring range, i.e., the higher rate of stirring inhibits the nucleation of ice crystals. This is because when the stirring strength is too strong, large grains can break into many small particles whose size does not meet the critical radius for nucleation, thereby reducing the nucleation rate. The exponent of suspension density is -1.465 , which is less than zero, indicating that the increase of suspension density did not facilitate the nucleation of ice crystals.

As the driving force of the formation of ice crystals, the degree of supercooling of solution has an important effect on the nucleation and growth of ice crystals. The exponent of supercooling degree in the equation of nucleation rate is 0.517 , which is larger than zero, indicating that the increase of supercooling can increase the nucleation rate considerably. This result is consistent with the theoretical analysis, i.e., the larger the supercooling, the faster the nucleation. In general, the kinetic order of primary nucleation is close to 10 , which is much larger than the kinetic order obtained in this work (0.517), suggesting that the mechanism of nucleation is secondary contact nucleation. As shown from Equation (14), the ice crystal growth rate increased along with the degree of supercooling, and it is proportional to the 4.036th power of supercooling. However, the nucleation rate is proportional to the 0.517th power of supercooling, which suggests that the impact of supercooling on the nucleation rate is much weaker than on the growth rate.

\subsection{Ice Crystal Size}

The average particle size of ice crystals was observed in 3\% ethylene glycolaqueous solution at stirring rates of 200, 300 and $400 \mathrm{rpm}$, respectively. The results are shown in Figure 10. Under different stirring rates, the average particle size of ice crystals is $45.95,44.04$ and $44.18 \mu \mathrm{m}$ with a standard deviation of $6.89,7.08$ and $6.55 \mu \mathrm{m}$, respectively. Obviously, the average particle size of ice crystalsis less affected by the stirring rate. In theory, the mixing breaks the ice crystals into smaller particles. Meanwhile, these existing ice crystals are subject to agglomeration and Ostwald ripening effect, which increase the size of ice crystals. When the crushing effect is equivalent to the agglomeration and Ostwald ripening effect, the average particle size of ice crystals is generally not changing with the stirring rate.

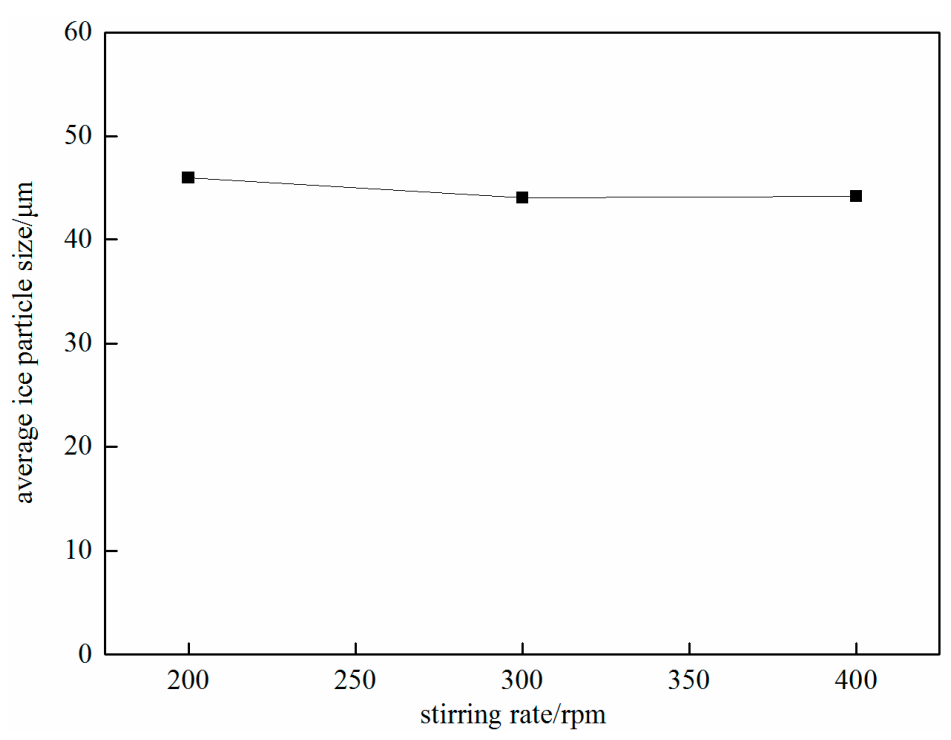

Figure 10. Effects of stirring rate on average particle size of ice crystals.

The average particle size of ice crystals was observed in 1\%, 3\% and 5\% ethylene glycol aqueous solution respectively and the results are shown in Figure 11. The average particle size of ice crystals 
decreased significantly alongside the initial concentration of ethylene glycol. The characteristics of the particle size of ice crystals in the ice slurry prepared by the scraped-surface method have been addressed in previous works, and the particle size of ice crystals was also found to decrease as concentration increased. This phenomenon can be explained as follows: the addition of ethylene glycol reduces the diffusion coefficient of water molecules in the aqueous solution. At the same time, the hydroxyl groups contained in the ethylene glycol molecule can form hydrogen bonds with the water molecules and break the hydrogen bonds between water molecules. In this way, ethylene glycol can inhibit the growth of ice crystals to a certain extent and refine the particles. The greater the content of ethylene glycol, the more pronounced the inhibitory effect is.

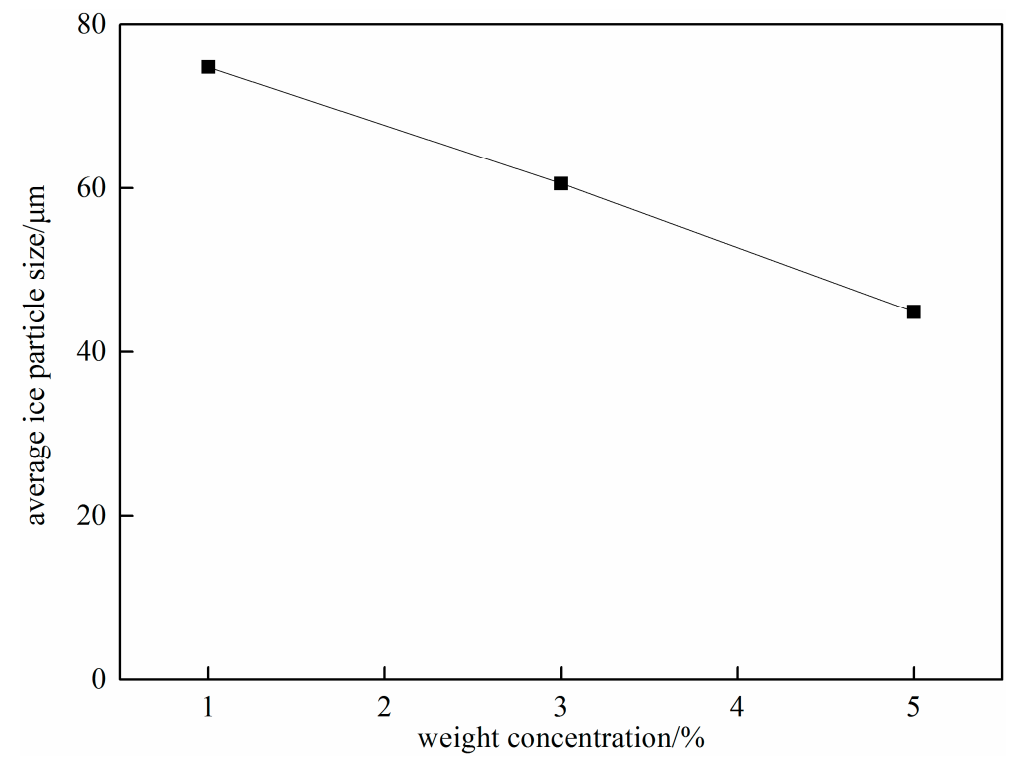

Figure 11. Effects of initial concentration on average particle size of ice crystals.

\section{Conclusions}

A systematic investigation is carried out to determine the thermodynamics and kinetics behavior of ice slurry crystallization in vacuum. The following conclusions can be drawn from the experiments:

(1) A new term, "supercooling crystallization pressure difference" or $\Delta p$, was established to characterize the supercooling degree. In addition, the effect of several parameters including additive concentration, cooling rate, and stirring rate on the instantaneous supercooling degree during crystal nucleation under vacuum environment were studied. These results show that the stirring rate has little effect on supercooling, the increase of cooling rate causes the increase of supercooling degree, and increasing initial concentration can reduce the supercooling degree.

(2) The kinetic mechanism underlying the nucleation process of ice crystals was illustrated. The equations of nucleation rate and growth rate were established. The study found that the increase of suspension density and stirring rate could not improve the nucleation of ice crystals. Meanwhile, the optical method of accelerating nucleation and growth is to increase the degree of supercooling.

(3) Stirring rate has a negligible effect on the average particle size of ice crystals. Ethylene glycol can inhibit the growth of crystal to a certain extent and reduce the average particle size.

Summarizing, the research of this article reveals the supercooling condition of ice slurry crystallization and the rules of nucleation and growth of ice crystals, as well as enriches the morphology study of ice crystals. Therefore, this study will be helpful in the design and control of industrial ice making. 
Acknowledgments: We gratefully acknowledge the support of National Natural Science Foundation of China (Nos. J1103303 and 51602054) and Program for Young Teacher Education and Research of Fujian Province (No. JA14053).

Author Contributions: Xi Liu conceived and designed the experiments; Kunyu Zhuang and Zheng Zhang performed the experiments; Shi Lin analyzed the data; Xi Liu wrote the paper; Xuelai Li modified the article.

Conflicts of Interest: The authors declare no conflict of interest.

\section{References}

1. Saito, A. Recent advances in research on cold thermal energy storage. Int. J. Refrig. 2002, 25, 177-189. [CrossRef]

2. Fang, G.Y.; Tang, F.; Cao, L. Dynamic characteristics of cool thermal energy storage systems—A review. Int. J. Green Energy 2016, 13, 1-13. [CrossRef]

3. Song, S.K.; Dong, L.J.; Zhang, Y.; Chen, S.; Li, Q.; Guo, Y.; Deng, S.F.; Si, S.; Xiong, C.X. Lauric acid/intercalated kaolinite as form-stable phase change material for thermal energy storage. Energy 2014, 76, 385-389. [CrossRef]

4. Song, S.K.; Dong, L.J.; Chen, S.; Xie, H.A.; Xiong, C.X. Stearic-capric acid eutectic/activated-attapulgiate compositeas form-stable phase change material for thermal energy storage. Energy Convers. Manag. 2014, 81, 306-311. [CrossRef]

5. Li, G.; Hwang, Y.H.; Radermacher, R. Review of cold storage materials for air conditioning application. Int. J. Refrig. 2012, 35, 2053-2077. [CrossRef]

6. Yao, Y.H.; Rismanchi, B. A review on cool thermal storage technologies and operating strategies. Renew. Sustain. Energy Rev. 2012, 16, 787-797. [CrossRef]

7. Kauffeld, M.; Wang, M.J.; Goldstein, V.; Kasza, K.E. Ice slurry applications. Int. J. Refrig. 2010, 33, 1491-1505. [CrossRef] [PubMed]

8. Bédécarrats, J.P.; David, T.; Castaing-Lasvignottes, J. Ice slurry production using supercooling phenomenon. Int. J. Refrig. 2010, 33, 196-204. [CrossRef]

9. Byrd, L.W.; Mulligan, J.C. A population balance approach to direct-contact secondary refrigerant freezing. AIChE J. 1986, 32, 1881-1888. [CrossRef]

10. Thongwilk, S.; Vorayos, N.; Kiatsiriroat, T.; Nuntaphan, A. Thermal analysis of slurry ice production system using direct contact heat transfer of carbon dioxide and water mixture. Int. Commun. Heat Mass Transf. 2008, 35, 756-761. [CrossRef]

11. Peng, Z.B.; Yuan, Z.L.; Liang, K.F.; Cai, J. Ice slurry formation in a concurrent liquid-liquid flow. Chin. J. Chem. Eng. 2008, 16, 552-557. [CrossRef]

12. Shin, H.T.; Lee, Y.P.; Jurng, J. Spherical-shaped ice particle production by spraying water in a vacuum chamber. Appl. Therm. Eng. 2000, 20, 439-454. [CrossRef]

13. Kim, B.S.; Shin, H.T.; Lee, Y.P.; Jurng, J. Study on ice slurry production by water spray. Int. J. Refrig. 2001, 24, 176-184. [CrossRef]

14. Lugo, R.; Fournaison, L.; Guilpart, J. Ice-liquid-vapour equilibria of ammonia and ethanol aqueous solutions applied to the production of ice-slurries: Prediction and experimental results. Chem. Eng. Process. 2006, 45, 66-72. [CrossRef]

15. Asaoka, T.; Saito, A.; Okawa, S.; Ito, T.; Izumi, N. Vacuum freezing type ice slurry production using ethanol solution 1st report: Measurement of vapor-liquid equilibrium data of ethanol solution at $20^{\circ} \mathrm{C}$ and at the freezing temperature. Int. J. Refrig. 2009, 32, 387-393. [CrossRef]

16. Asaoka, T.; Saito, A.; Okawa, S.; Kumano, H.; Hozumi, T. Vacuum freezing type ice slurry production using ethanol solution 2nd report: Investigation on evaporation characteristics of ice slurry in ice production. Int. J. Refrig. 2009, 32, 394-401. [CrossRef]

17. Zhang, X.L.; Han, Z.; Li, Z.W. Analysis on IPF influencing factors for vacuum binary ice making method. Int. J. Therm. Sci. 2013, 67, 210-216. [CrossRef]

18. Okawa, S.; Saito, A.; Suto, H. The experimental study on freezing of supercooling water usingmetallic surface. Int. J. Refrig. 2002, 25, 514-520. [CrossRef] 
19. Faucheux, M.; Muller, G.; Havet, M.; LeBail, A. Influence of surface roughness on the supercooling degree: Case of selected water/ethanol solutions frozen on aluminum surfaces. Int. J. Refrig. 2006, 29, 1218-1224. [CrossRef]

20. Chégnimonhan, V.; Josset, C.; Peerhossaini, H. Ice slurry crystallization based on kineticphase-change modeling. Int. J. Refrig. 2010, 33, 1559-1568. [CrossRef]

21. Kousksou, T.; Jamil, A.; Arid, A.; Jegadheeswaran, S.; Zeraouli, Y. Crystallisation kinetics with nucleation phenomenon: Ice slurry system. Int. J. Refrig. 2012, 35, 1921-1930. [CrossRef]

22. Pronk, P.; Hansen, T.M.; Infante Ferreira, C.A.; Witkamp, G.J. Time-dependent behavior of differentice slurries during storage. Int. J. Refrig. 2005, 28, 27-36. [CrossRef]

23. Inada, T.; Modak, P.R. Growth control of ice crystals by poly (vinyl alcohol) and antifreeze protein in ice slurries. Chem. Eng. Sci. 2006, 61, 3149-3158. [CrossRef]

24. Zhao, Y.; Kamaraju, V.K.; Hou, G.Y.; Powera, G.; Donnellana, P.; Glennona, B. Kinetic identification and experimental validation of continuous plug flow crystallization. Chem. Eng. Sci. 2015, 133, $106-115$. [CrossRef]

25. Wang, Y.L.; Ma, S.Y.; Lv, X.D. Determination of reactive crystallization kinetics of 5-(difluromethoxy)-2-mercapto-1H-benzimidazole in a batch crystallizer. Cryst. Res. Technol. 2012, 47, 848-862. [CrossRef]

26. Cao, Y.H.; Duan, X.H.; Pei, C.H. Study on crystallization kinetics and the crystal internal defects of HMX. Cryst. Res. Technol. 2013, 48, 29-37. [CrossRef]

27. Sun, X.X.; Sun, Y.Z.; Yu, J.G. Cooling crystallization of aluminum sulfate in pure water. J. Cryst. Growth 2015, 419, 94-101. [CrossRef]

28. Zhu, G.Y.; Li, H.Q.; Li, S.P.; Hou, X.J.; Xu, D.H.; Lin, R.Y.; Tang, Q. Crystallization behavior and kinetics of calcium carbonate in highly alkaline and supersaturated system. J. Cryst. Growth 2015, 428, 16-23. [CrossRef]

29. Delahaye, A.; Fournaison, L.; Guilpart, J. Characterisation of ice and THF hydrate slurry crystal size distribution by microscopic observation method. Int. J. Refrig. 2010, 33, 1639-1647. [CrossRef]

30. Suzuki, H.; Nakayama, K.; Komoda, Y.; Usui, H.; Okada, K.; Fujisawa, R. Particle size characteristics of ice slurry treated with surfactants and brines. J. Chem. Eng. Jpn. 2009, 42, 447-451. [CrossRef]

31. Saito, A.; Okawa, S.; Akira, T. Fundamental research on external factors affecting the freezing of supercooling water. Int. J. Heat Mass Transf. 1992, 35, 2527-2536.

(C) 2017 by the authors. Licensee MDPI, Basel, Switzerland. This article is an open access article distributed under the terms and conditions of the Creative Commons Attribution (CC BY) license (http:/ / creativecommons.org/licenses/by/4.0/). 